\title{
Human Genetic Disorders Associated with Genome Instability, Premature Aging and Cancer Predisposition
}

\author{
Razmik Mirzayans* and David Murray \\ Department of Oncology, University of Alberta, Cross Cancer Institute, Edmonton, Alberta T6G 1Z2, Canada
}

\begin{abstract}
Our genetic material is constantly damaged by internal sources such as reactive oxygen species and external sources such as ionizing radiation and sunlight. However, we seldom notice these injuries because our cells possess elegant DNA surveillance networks that serve to maintain cellular homeostasis. These networks are complex signal transduction pathways that coordinate cell cycle checkpoints and DNA repair processes to eliminate DNA damage, as well as invoking pathways such as sustained growth arrest (i.e., accelerated senescence) and apoptotic cell death to eliminate injured cells from the proliferating population. The p53 tumor suppressor protein and its downstream effector p21 are key regulators of these various responses. Failure of cells to properly activate p53/p21-mediated events following genotoxic stress may lead to the development of genomic instability and the emergence of malignant cells which exhibit stem cell-like properties. It is therefore not surprising that defects in major players of the DNA surveillance networks are the underlying cause for numerous debilitating human genetic disorders that are characterized by genomic instability, premature aging, and cancer proneness. In this article, we first provide an update on the role of the p53 signaling pathway in determining the fate of human cells following exposure to DNA-damaging agents. We next review the clinical and laboratory features of the most extensively studied human genome instability disorders including xeroderma pigmentosum, Cockayne syndrome, ataxia telangiectasia, and Li-Fraumeni syndrome, and discuss the current knowledge on the biological consequences of deregulated p53 signaling in cells derived from patients with such disorders.
\end{abstract}

Keywords: Human genome instability disorders, p53 signaling, apoptosis, accelerated senescence, endopolyploidy.

\section{INTRODUCTION}

Our genome is continuously exposed to potentially deleterious genotoxic events from both endogenous sources, resulting from cellular metabolism or routine errors in DNA replication and recombination, and exogenous sources such as ionizing radiation, ultraviolet light (UV), and chemical mutagens. Genome integrity and cellular homeostasis are maintained through elegant DNA surveillance networks that serve to recognize the DNA damage and facilitate DNA repair, or to eliminate highly injured cells from the proliferating population. Mutations in the genes that encode the key players of the DNA surveillance networks are the underlying cause for a number of genome-instability syndromes, disorders that are often associated with a heightened predisposition to cancer (Table 1).

The focus of this review is to: (i) provide an update on the roles of the p53 tumor suppressor protein and its key downstream effector $\mathrm{p} 21$ in determining the fate of human cells following genotoxic stress; (ii) highlight the clinical and laboratory characteristics of genomic-instability syndromes such as xeroderma pigmentosum and related disorders, ataxia telangiectasia and related disorders, LiFraumeni syndrome, Werner syndrome and related disorders; and (iii) discuss the biological consequences of the aberrant activation of p53 signaling in cells derived from patients with some of these disorders.

*Address correspondence to this author at the Department of Oncology, University of Alberta, Cross Cancer Institute, Edmonton, Alberta T6G 1Z2, Canada; Tel: 780-432-8897; Fax: 780-432-8428;

E-mail: razmikm@cancerboard.ab.ca

\section{P53 SIGNALING AND CELLULAR RESPONSE TO DNA DAMAGE}

The human p53 tumor suppressor is a 393 amino acid tetrameric transcription factor consisting of five structural and functional domains: an $\mathrm{N}$-terminal acidic transcriptional transactivation domain, a proline-rich regulatory domain, a central DNA-binding domain, an oligomerization domain, and a C-terminal domain involved in the regulation of DNA binding [1]. The N-terminal domain is required for activating downstream target genes. The proline-rich domain is responsible for interaction with various proteins that activate apoptotic signaling. The central DNA-binding domain is comprised of $\beta$-sheets that support flexible loops and helices that facilitate sequence-specific DNA binding. The oligomerization domain is comprised of a $\beta$-strand, a tight turn, and an $\alpha$-helix, through which p53 molecules interact to form dimers, and dimers interact to form tetramers. Tetramerization of p53 is essential for its ability to function as a transcription factor. The C-terminal domain contains nuclear localization sequences as well as a negative regulatory region that binds short non-specific DNA sequences and prevents the binding of sequence-specific DNA to the central domain of p53.

In unstressed cells, the p53 protein undergoes rapid turnover, and is thus maintained at low steady state levels that restrict its impact on cell fate [2]. DNA damage and other forms of stress trigger a series of post-translational modifications on p53 that contribute to its stabilization, nuclear accumulation and biochemical activation [3, 4]. These modifications include phosphorylation, acetylation, ribosylation, $O$-glycosylation, ubiquitination and sumoylation [5-7]. The phosphorylation sites Ser15, Thr18 and 
Table 1. Some Clinical and Molecular Characteristics of the most Extensively Studied Human Genome Instability Disorders

\begin{tabular}{|c|c|c|c|c|}
\hline Disorder & Mode of Transmission & Cancer Proneness & Defective Protein & Defective Function \\
\hline \hline Xeroderma pigmentosum & Autosomal recessive & Yes & $\begin{array}{c}\text { XPA through XPG; } \\
\text { DNA polymerase } \eta\end{array}$ & $\begin{array}{c}\text { NER (XPA through XPG); } \\
\text { Postreplication repair (XPV) }\end{array}$ \\
\hline Cockayne syndrome & Autosomal recessive & No & CSA, CSB & NER (TCR) \\
\hline Tricothiodystrophy & Autosomal recessive & No & XPB; XPD, TTDA & NER (GGR) \\
\hline Ataxia telangiectasia & Autosomal recessive & Yes & ATM & ATM signaling \\
\hline Nijmegen breakage syndrome & Autosomal recessive & Yes & MSB repair \\
\hline AT-like disorder & Autosomal recessive & No & p53; Chk2 & p53/Chk2 signaling repair \\
\hline Li-Fraumeni syndrome & Autosomal dominant & Yes & WRN & DNA helicase \\
\hline Werner syndrome & Autosomal recessive & Yes & BS & DNA helicase \\
\hline Bloom syndrome & Autosomal recessive & Yes & RTS & DNA helicase \\
\hline Rothmund-Thompson syndrome & Autosomal recessive & Yutosomal recessive & Yes & FANCA, B, C, D1, D2, \\
\hline Fanconi Anemia & & DNA h, L and M & DNA cross-link repair \\
\hline
\end{tabular}

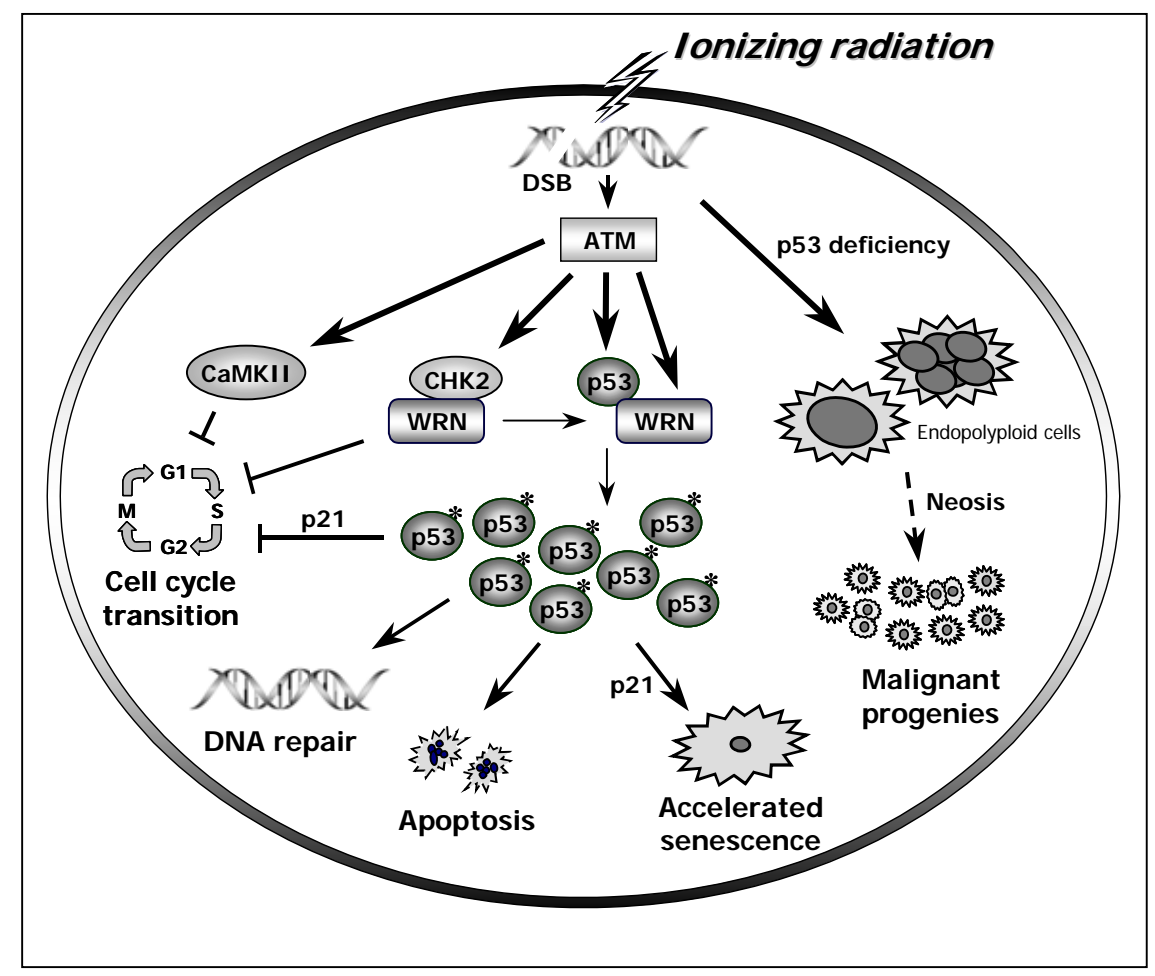

Fig. (1). Responses triggered by ionizing radiation in human cells. Arrows indicate stimulation and T-shaped lines indicate inhibition. DNA double-strand breaks (DSB) induce rapid activation of the ATM protein kinase through a posttranslational mechanism, which then mediates the phosphorylation of target proteins including p53, CHK2 and WRN (defective in Werner syndrome patients). Phosphorylation of p53 results in its accumulation in the nucleus and transcriptional activation of $p 21^{W A F 1}$ and other $\mathrm{p} 53$-responsive genes. Depending on the extent of genomic injury and the genetic background of the cells, activation of the p53 pathway may promote survival through activating G1/S and G2/M checkpoints and DNA repair processes, or may lead to p53-directed apoptosis or p21-directed accelerated senescence. WRN and CHK2 also contribute to phosphorylation of p53 and activation of downstream events [93, 94]. The radiation-responsive S-phase checkpoint is dependent on WRN [95] and $\mathrm{Ca}^{2+} /$ calmodulin-dependent protein kinase II (CaMKII) [118], but not the p53-p21 axis [118]. Failure of the cells to implement these responses can lead to the development of mononucleated and multinucleated "giant" cells, which have the potential of undergoing neotic cell division, eventually leading to the emergence of malignant and therapy-resistant progenies [37].

Ser20 are critical for stabilization of the p53 protein. A number of kinases have been implicated in phosphorylation of p53, including members of the phosphatidylinositol 3kinase superfamily of protein kinases $[8,9]$. 


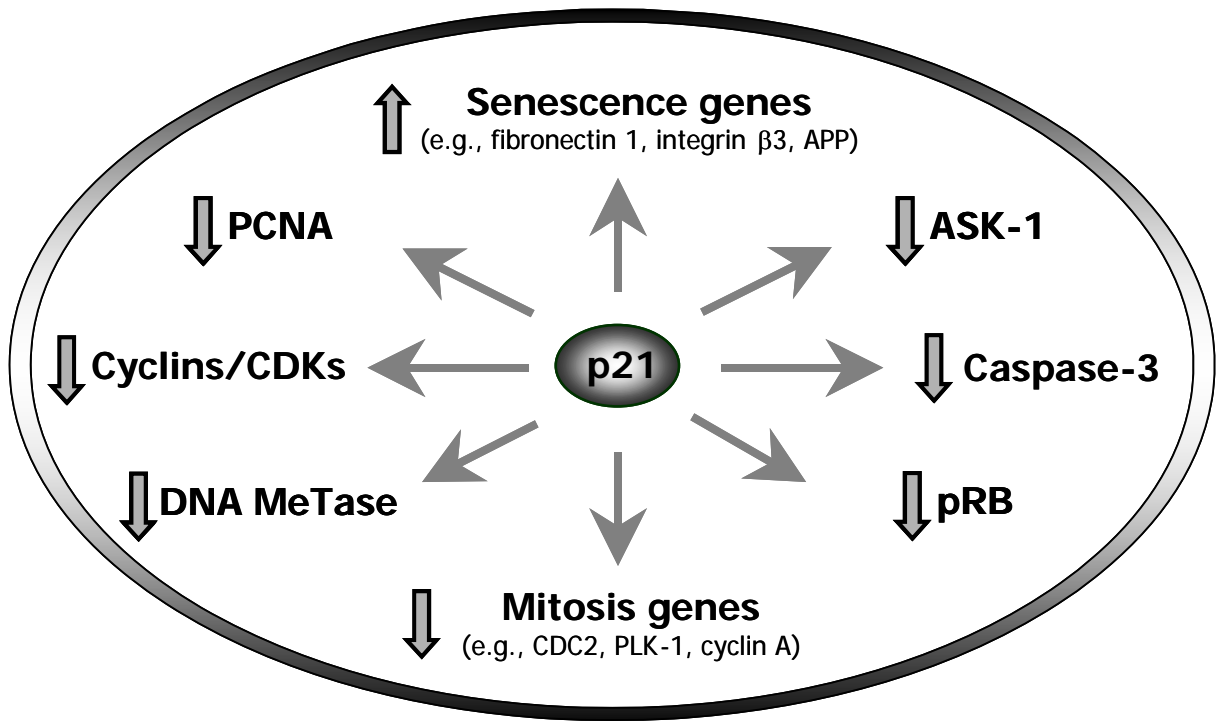

Fig. (2). Multiple functions of p21. Exposure of p53-proficient human cells to DNA-damaging agents results in p53-dependent transcriptional activation of p21. In the nucleus, p21 inhibits DNA synthesis by interacting with PCNA and cyclin/CDK complexes [24], down-regulates pRB [29], interferes with DNA methyltransferase (MeTase) activity [123], stimulates transcription of a series of genes involved in senescence, and suppresses the transcription of numerous genes involved in mitosis [25, 26]. In the cytoplasm, p21 interacts with ASK-1, down-regulates the MAPK cascade, and results in resistance of cells to undergoing apoptotic cell death [27]. In addition, p21 forms a complex with procaspase 3, resulting in suppression of caspase 3-mediaed apoptosis [28].

\section{Multiple Functions of p53}

Activation of the p53 network following genotoxic stress either serves to promote cell survival by activating cell cycle checkpoints and facilitating DNA repair, or eliminates the injured cells from the proliferating population, for example by inducing apoptotic cell death or a senescence-like growth arrest (herein called accelerated senescence) (Fig. (1)). Many of the effects of $\mathrm{p} 53$ are attributed to transcriptional activation of $\mathrm{p} 53$-responsive genes in general, and $p 21^{W A F 1}$ in particular [10-13]. The protein encoded by this gene (p21) is known to down-regulate apoptosis, to activate cell cycle checkpoints, and to switch on the senescence program (see below). In addition to $\mathrm{p} 21$, several other proteins that are transcriptionally regulated by $\mathrm{p} 53$ also influence apoptosis. These include the pro-apoptotic proteins PUMA (p53 upregulated modulator of apoptosis), BAX (BCL-2Associated X Protein) and NOXA (the Latin word for damage) $[14,15]$.

Accumulating evidence indicates that p53 also directly modulates the transmission of specific signals by interacting with other cellular proteins. For example, p53 interacts with key players of different DNA repair pathways, including DNA double strand break (DSB) repair [16-19] and nucleotide excision repair [20]. In addition, the proline-rich domain of p53 directly mediates apoptotic signaling independent of the transcriptional transactivation domain of the protein [21]. This proline-rich domain also contains a motif that serves as a docking site in the transmission of signals that inhibit DNA synthesis, resulting in transactivation-independent inhibition of growth [22]. The p53 protein also functions as a regulator of the complex intercellular communication network that is now well documented to play a pivotal role in determining cell fate following genotoxic stress [23].

\section{Multiple Functions of p21}

The p21 protein is a member of the CIP/KIP family of protein kinase inhibitors. It exerts its effect on the cell by various mechanisms (Fig. (2)). The C-terminus of p21 suppresses DNA synthesis by interacting with proliferating cell nuclear antigen (PCNA), an auxiliary factor for DNA polymerase $\delta$ [24]. The N-terminus of p21 binds to cyclindependent kinases (CDKs) and inhibits their ability to phosphorylate the retinoblastoma protein (pRB), an activity that is required for progression of cells from $\mathrm{G} 1$ to $\mathrm{S}$ phase [24]. Prolonged nuclear accumulation of $\mathrm{p} 21$ following genotoxic stress is known to drive accelerated senescence, and this response is associated with p21-dependent downregulation of genes involved in mitosis and up-regulation of genes mediating cellular senescence $[25,26]$. In addition to exerting these responses, under certain conditions (e.g., activation of the phosphatidylinositol 3-kinase/AKT signaling pathway) the $\mathrm{p} 21$ protein may be sequestered in the cytoplasm, where it interacts with apoptosis signalregulating kinase 1 (ASK-1), down-regulates the stressinduced mitogen-activated protein kinase (MAPK) cascade, and results in resistance of cells to apoptosis induced by genotoxic agents [27]. Another mechanism by which p21 might down-regulate apoptosis is through interaction with procaspase 3 , resulting in suppression of caspase 3-mediaed apoptosis [28]. The p21 protein has also been reported to dephosphorylate $\mathrm{pRB}$, as well as to inactivate $\mathrm{pRB}$ through proteasome-mediated degradation [29]. In short, p21 plays a key role in determining cell fate following genotoxic stress not only as an activator of the G1/S cell cycle checkpoint, 


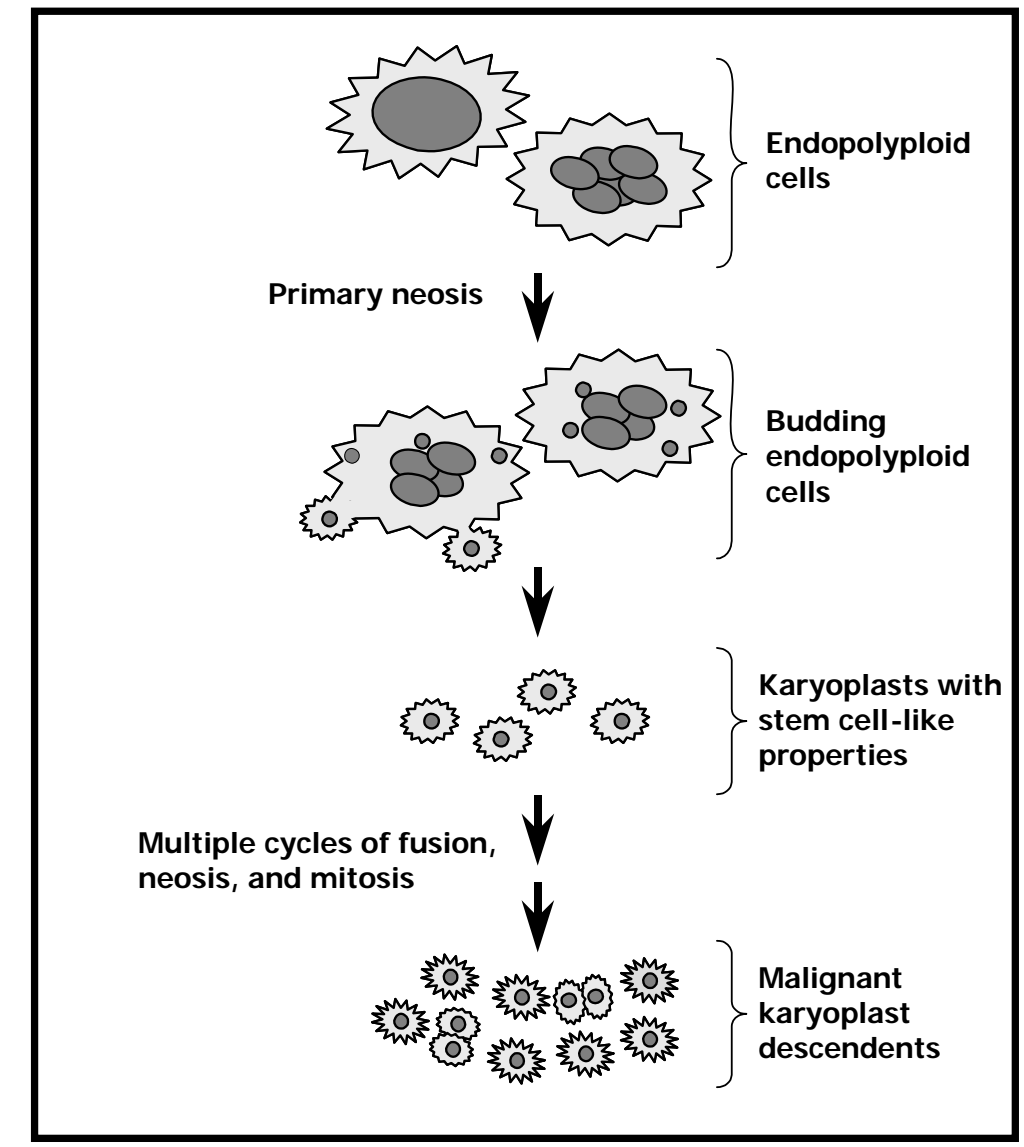

Fig. (3). Fate of endopolyploid giant cells. Failure of cells to properly activate cell cycle checkpoints following exposure to DNA-damaging agents may lead to the development of endopolyploid giant cells with massive DNA contents [30]. The majority of such giant cells may be eliminated from the proliferating population by accelerated senescence, apoptosis or other modes of cell death. A small proportion of giant cells, however, may retain viability and undergo neotic cell division, which is characterized by karyokinesis via nuclear budding followed by asymmetric cytokinesis, resulting in the generation of small mononuclear "karyoplasts" (also called Raju" cells) [32-37]. These karyoplasts cells may undergo multiple cycles of cell fusion/neosis/mitosis, eventually giving rise to highly metastatic and therapy resistant descendants $[36,37]$.

but also as a regulator of transcription, activator of accelerated senescence, down-regulator of apoptosis, and regulator of the $\mathrm{pRB}$ tumor suppressor.

\section{Biological Consequences of the Failure to Implement p53/p21-Mediated Responses}

Cells that fail to properly activate the p53 pathway in response to genotoxic stress may replicate their genome and execute mitosis despite carrying high levels of DNA damage and chromosomal aberrations [30]. This can result in the development of micronucleated giant cells (containing subgenomic fragments in multiple micronuclei), as well as endopolyploid giant cells, encompassing cells with a single, but markedly enlarged, nucleus (with a DNA content at least four times greater than that of unirradiated cells), and cells with several nuclei (sometimes as many as ten). Such features of "mitotic catastrophe" were originally considered to represent aberrations of dying cells (reviewed in [30]). However, studies with p53-deficient human cell lines exposed to ionizing radiation $(10 \mathrm{~Gy})$ have revealed that a subset of endopolyploid giant cells are protected against apoptosis [33], exhibit efficient repair of DSBs [33], and undergo a complex breakdown and sub-nuclear reorg- anization, ultimately resulting in the genesis of rapidly propagating progenies [30-34]. The Aurora B kinase has been recently demonstrated to play a crucial role in supporting the long-lasting reproductive potential of endopolyploid giants [34]. Unlike endopolyploidy that may provide a survival advantage, micronucleation appears to be associated with death, as totally micronucleated cells do not express Aurora B kinase and fail to undergo mitosis [34].

There is also evidence that the progeny of endopolyploid giant cells might be generated not by the classical types of cell division (mitosis), but rather through the process of neosis, which resembles division of the budding yeast [3543]. Computerized video time-lapse microscopy has revealed that although many of these endopolyploid cells cease to divide, some endopolyploid cells may produce numerous (50 or more) small cells with little cytoplasm (called "karyoplast" or "Raju" cells) via the nuclear budding process of neosis [35, 38]. As extensively discussed by Rajaraman and his colleagues [35, 38], karyoplast cells that emerge from each neotic endopolyploid cell might regain mitotic activity and transiently display certain stem cell-like properties (e.g., extended mitotic life span, expression of telomerase, and potential to differentiate), and subsequently 
experience a complex life cycle eventually leading to the development of highly metastatic cells (also see Fig. (3)). This parasexual mode of somatic reduction division is now fairly well characterized and has been documented for a variety of p53-deficient murine and human cell lines [36, 3840]. In addition, exposure of p53-deficient cell cultures to DNA-damaging agents has been demonstrated to yield neosis-derived karyoplast cells that exhibit marked resistance to cancer therapeutic agents, suggesting that such events may contribute to the recurrence of therapy-resistant malignancies $[35-38,41,42]$. The finding that the development of endopolyploid cells can represent a mechanism of survival in p53-deficient cultures has been the subject a special review issue of Cell Biology International, with an Editorial article entitled "Endopolyploidy... survival of the fattest" [43].

\section{GENOME INSTABILITY DISORDERS}

The best-studied human genome instability disorders are listed in Table 1. These disorders can be loosely divided into four groups. The sunlight hypersensitivity disorders xeroderma pigmentosum, Cockayne syndrome, and tricothiodystrophy; the ionizing radiation hypersensitivity disorders ataxia telangiectasia, Nijmegen breakage syndrome, and ataxia telangiectasia-like disorder; the LiFraumeni syndrome, characterized by a wide spectrum of tumors affecting children and young adults; and the progeroid disorders Werner syndrome, Bloom syndrome, Rothmund-Thompson syndrome, and Fanconi Anemia, all of which are associated with a deficiency in a DNA helicase activity. Whereas the Li-Fraumeni syndrome is an autosomal dominantly transmitted disorder, all other conditions listed in Table $\mathbf{1}$ are inherited in an autosomal recessive pattern. The clinical and laboratory (i.e., cellular and molecular) characteristics of these disorders are described blow.

\section{Sunlight Hypersensitivity Disorders}

Xeroderma pigmentosum (XP) is characterized by extreme sensitivity to UV resulting in greater than 1000-fold increased risk of developing sunlight-induced skin cancer. Other clinical features of XP include blistering or freckling on minimal sun exposure, premature aging of skin, lips, eyes, mouth and tongue, blindness, progressive neurological complications such as developmental disabilities and mental retardation [44-46]. Cells cultured from XP patients are hypersensitive to UV in terms of cell killing, mutagenesis and in vitro transformation [44, 47, 48]. Eight genetic forms of XP have been identified, designated groups A through G, that are deficient in early steps of nucleotide excision repair (NER), and group variant, that is deficient in postreplication repair. The NER process employs an array of over 30 proteins that detect bulky DNA lesions such as UV-induced cyclobutane pyrimidine dimers and 6-4 photoproducts, excise the damaged strand, and synthesize new DNA using the complementary strand as a template. Two sub-pathways of NER function in human cells: global genome repair (GGR) and transcription-coupled repair (TCR), which operate on the whole genome and the transcribed strand of expressed genes, respectively [49]. XP complementation groups A, B, D, E, F and G are deficient in both GGR and TCR, whereas XP-C is deficient in GGR only. The XP variant group, on the other hand, is defective in DNA polymerase $\eta$, which catalyzes the efficient and accurate translesion synthesis of DNA past bulky lesions induced by UV and UV-mimetic chemicals [50].

Cockayne syndrome (CS) is characterized by postnatal growth failure, neurological dysfunction, cachectic dwarfism, photosensitivity, sensorineural hearing loss and retinal degradation $[51,52]$. The skin of CS patients is frail, slightly wrinkled and sensitive to light. Over time, sun exposure causes characteristic skin changes. The head of CS patients is small and their eyes deeply set as a result of their brain failing to grow normally. Two genetic forms of CS have been identified, designated CSA and CSB [53]. The protein defective in CSA patients belongs to the "WD repeat" family of structural and regulatory proteins that lack enzymatic activity [54]. The protein defective in CSB patients is a member of the SW1/SNF family of ATPases, which facilitate transcription by altering the structure of the chromatin [55]. Cells derived from all CS patients are defective in the TCR subpathway of NER, but carry out the GGR subpathway with normal efficiency. However, not all clinical and cellular features of CS can be explained by defective TCR of bulky DNA lesions. The basis for this conclusion is that CS patients, with a specific defect in TCR, nonetheless display more severe symptoms than most XP patients (e.g., groups A and G) in which both the TCR and GGR subpathways of NER are affected. Accordingly, a role of the CS proteins outside NER has been suggested, such as an auxiliary function in transcription $[56,57]$ and/or in the TCR of non-bulky DNA lesions [58-61]. Indeed, CS cells exhibit a defect in the TCR of oxidative DNA damage [60, $61]$, underscoring the possible contribution of unrepaired oxidative DNA lesions in the etiology of CS.

Tricothiodystrophy (TTD) is characterized by brittle hair and nails with reduced sulfur content, mental retardation, ichthyotic skin, and reduced stature [62]. Most TTD patients present with UV sensitivity but no increased incidence of cancer. Cells derived from UV-photosensitive TTD patients have a defect in GGR but not in TCR, similar to XP complementation group C. Surprisingly, however, genetic analysis has revealed that some photosensitive TTD patients have mutations in the XPB gene, and some in the XPD gene; such TTD patients have therefore been designated XPB and XPD, respectively $[63,64]$. Another group of TTD patients carry normal alleles of the genes that are mutated in all complementation groups of XP; this group is designated TTDA [63, 64]. The basis for the paradoxical observations that mutations in a single gene (e.g., XPD) can affect only GGR in TTD patients but both GGR and TCR in XP patients, and that mutations in a single gene can be associated with two clinically diverse disorders (i.e., XP and TTD), remains largely unexplained.

\section{Ionizing Radiation Hypersensitivity Disorders}

Ataxia telangiectasia (AT) is characterized by progressive neurovascular degeneration, immunodeficiency, impaired organogenesis, premature aging and endocrine dysfunction [65-67]. AT patients are also prone to lymphoproliferative neoplasia and respond untowardly to radiotherapy for cancer treatment $[67,68]$. The gene mutated in AT, called ATM (AT mutated), encodes a 350-kDa serinespecific protein kinase. The C-terminal domain of the ATM 
protein shares the kinase signature of the phosphatidylinositol 3-kinase superfamily of proteins, which are involved in the regulation of cell cycle progression, DNA damage processing, and maintenance of genomic stability and cellular homeostasis [8, 69]. The ATM protein plays a central role in orchestrating the various responses triggered by ionizing radiation and other agents that induce DNA DSBs (Fig. (1)). Exposure of normal human cells to such agents results in rapid activation of ATM, which then phosphorylates hundreds of target proteins involved in DNA repair and replication [70], including p53 (mutated in most Li-Fraumeni syndrome patients) and WRN (defective in Werner syndrome patients). ATM also phosphorylates the Cterminal tail of the core histone H2AX molecules surrounding DSBs [71, 72]. This phosphorylation marks the site of damage and nucleates the formation of damage response and repair complexes. Consistent with these properties of ATM, cells derived from AT patients exhibit defective clonogenic survival, excessive genetic instability, impaired activation of cell cycle checkpoints, and defective repair of DSBs following exposure to ionizing radiation and radiomimetic agents $[66,67,73,74]$. A prominent feature of AT cells is their failure to suppress DNA synthesis following exposure to ionizing radiation. We have reported that this socalled radioresistant DNA synthesis phenotype of AT cells can be corrected by diffusible factors secreted from normal cells into the culture medium, or by simply treating AT cells with prostaglandin E2 [75]. These findings suggest that eicosanoids such as prostaglandin E2 may assume the role of an extracellular signaling modulator of the S-phase checkpoint in AT cells exposed to ionizing radiation, mediating DNA synthesis shutdown via an alternative, ATM-independent signal transduction pathway [75]. Identification of exogenous factors capable of compensating for the ATM function could potentially provide a practical strategy for improved management of AT patients without the need for ATM gene replacement.

Nijmegen breakage syndrome (NBS) is characterized by immunodeficiency, microcephaly, mental retardation, increased incidence of lymphoid cancers and extreme sensitivity to ionizing radiation $[76,77]$. The gene mutated in NBS, NBS1, encodes a protein that is a downstream substrate of ATM and is involved in the repair of DSBs.

AT-like disorder (ATLD) is characterized by cerebellar degeneration, chromosomal instability, and ionizing radiation sensitivity. Unlike AT and NBS patients, ATLD patients are not immunodeficient and show no increased incidence of cancer. The gene defective in ATLD encodes the MRE11 protein, which forms a trimer with NBS1 and RAD50 proteins and participates in DSB rejoining [78, 79].

\section{Li-Fraumeni Syndrome}

Li-Fraumeni Syndrome (LFS) is characterized by a marked increase in familial disposition to cancers, including sarcomas, carcinomas of the breast, brain, and adrenal gland, and acute leukemia [80]. The majority of LFS patients harbor germline mutations in one allele of the $p 53$ gene, with the mutant protein often causing transdominant inhibition of the wild-type p53 function [81, 82]. Germline mutations in the CHK2 gene, which encodes the CHK2 checkpoint kinase, have also been found in some members of LFS families [83]. Despite the presence of such mutations in affected members of most LFS kindreds, the molecular genetics of LFS are still not completely understood. It is likely that p53/CHK2 mutations are only one major event, and that LFS may be associated with abnormal functioning of multiple DNA-damage response pathways. Noncancerous dermal fibroblast strains derived from LFS patients that harbor p53 mutations have been instrumental in demonstrating a role for wild-type p53 in the repair of DNA damage induced by UV [84-87] and ionizing radiation [74, 86]. LFS strains with compromised or absence of wild-type p53 function exhibited DNA repair deficiencies after exposure to these agents.

\section{Progeroid Disorders Exhibiting DNA Helicase Deficiency}

Werner syndrome (WS) is the prototype progeroid disorder, characterized by graying and thinning of the hair, scleroderma-like skin changes, ocular cataracts, diabetes, atherosclerosis, osteoporosis, and high incidence of thyroid cancer, melanoma, and various sarcomas [88, 89]. The protein defective in WS patients (WRN) belongs to the RecQ family of helicases and possesses multiple DNA-metabolic functions such as $3^{\prime} \rightarrow 5^{\prime}$ exonuclease, DNA helicase and DNA-dependent ATPase activities [90-93]. WRN also directly interacts with p53 in response to genotoxic stress [94, 95]. This interaction contributes to p53 activation, resulting in increased expression of p53 target genes such as $p 21^{W A F I}, B A X, p 53 R 2$, and eventual phenotypic outcomes; namely, accelerated senescence, apoptosis, or repair. WRN undergoes phosphorylation by ATM and ATR (ATM and Rad3-related) specifically in response to agents that induce replication fork stalling [96], suggesting a role for WRN in the S-phase checkpoint. These and related findings have therefore established the existence of a cross-talk between WRN and key players of the DNA-damage surveillance network (e.g., ATM, ATR, CHK2, p53), suggesting the possibility that such cross talk may be important for maintaining genomic integrity and cellular homeostasis, and for preventing the accumulation of genetic abnormalities that can lead to cancer.

Bloom Syndrome (BS) is characterized by short stature, a narrow face with prominent nose, skin color changes in the face which are more noticeable after sunlight exposure, butterfly-shaped facial rash, a high pitched voice, an increased susceptibility to infection and respiratory diseases and a markedly increased susceptibility to a wide range of cancers, especially to leukemia and lymphoma [97, 98]. Cells derived from BS patients exhibit cytogenetic abnormalities including excessive chromosome breaks and sister chromatid exchanges [99]. The gene defective in Bloom syndrome is called $B L M$, which encodes a $3^{\prime} \rightarrow 5^{\prime}$ DNA helicase identified as a member of the RecQ family [100]. The BLM protein is phosphorylated and accumulates through an ATM-dependent pathway and appears to play a role in the $\mathrm{G} 2 / \mathrm{M}$ checkpoint following exposure to ionizing radiation [101].

Rothmund-Thompson syndrome (RTS) is characterized by growth retardation, photosensitivity with poikilodermatous skin changes (i.e., combination of atrophy, telangiectasia, and pigmentary changes), juvenile cataracts, early graying and hair loss, hypogonadism, and an increased 
prevalence of skin cancer and sarcomas [102]. Like the WRN and BLM proteins, the protein defective in RTS patients is a member of the RecQ family of helicases [103].

Fanconi anemia (FA) is characterized by congenital defects, bone marrow failure, short stature, infertility, skeletal anomalies, and increased incidence of solid tumors and leukemias [104]. FA patients are diagnosed on the basis of haematological abnormalities such as aplastic anemia, myelodysplastic syndrome, and acute myeloid leukaemia [105]. At the cellular level, a distinguishing and diagnostic feature of FA is chromosomal instability and cellular hypersensitivity to mitomycin $\mathrm{C}$ and other agents that induce DNA interstrand crosslinks [106]. Patients with FA are categorized into several complementation groups, including FANCA, B, C, D1, D2, E, F, G, I, J, L and M [107]. Eight FA proteins (FANCA, B, C, E, F, G, L, and M) appear to form a nuclear core complex possessing a putative DNA helicase (FANCM) and an E3 ubiquitin ligase (FANCL) subunit. Following formation of DNA crosslinks, the core complex mediates mono-ubiquitination of FANCD2, resulting in translocation of FANCD2 to DNA damage foci containing BRCA1 [108], BRCA2 [109], and the MRE11RAD50-NBS1 complex [110]. The precise role of FANCD2 in DNA repair remains unknown.

\section{BIOLOGICAL CONSEQUENCES OF DEREGU- LATED P53 SIGNALING IN PATIENTS WITH GENOME INSTABILITY SYNDROMES}

Our laboratory has contributed to the understanding of the biological consequences of the aberrant activation of the p53 signaling pathway following exposure to DNAdamaging agents in cells derived from XP, CS, LFS and AT patients. The outcome of these and related studies are discussed below.

\section{UV-Triggered Apoptosis and Accelerated Senescence in NER-Proficient and -Deficient Cells}

Compared to NER-proficient cells, NER-deficient cells from XP and CS patients exhibit a markedly increased ability to up-regulate p53 following exposure to UVC (254 $\mathrm{nm}$ ) or the UV-mimetic agent 4-nitroquinoline-1-oxide [87, 111, 112]. NER-deficient cells also show abnormally increased sensitivity to the killing effects of these agents when evaluated by the clonogenic assay. This hypersensitivity response has often been ascribed to p53mediated apoptotic cell death. However, ten years ago we reported a threshold effect for UVC-induced apoptosis in normal human fibroblasts. Thus, normal fibroblast cultures contained a significant proportion of apoptotic cells after exposure to supralethal fluences of UVC (e.g., $30 \mathrm{~J} / \mathrm{m}^{2}$, resulting in $>99 \%$ loss of clonogenic potential), but not after exposure to $15 \mathrm{~J} / \mathrm{m}^{2}$ or lower fluences [87]. In addition, we have recently demonstrated the existence of a threshold for UVC-induced apoptosis in NER-deficient fibroblast strains representing the XP-A, XP-G, CS-A and CS-B complementation groups, albeit shifted to lower fluences as compared to the threshold seen with normal fibroblasts [113]. We observed little, if any, induction of apoptosis in normal human fibroblasts exposed to $15 \mathrm{~J} / \mathrm{m}^{2}$, in XP-A and XP-G fibroblasts exposed to $2 \mathrm{~J} / \mathrm{m}^{2}$, and in CS-A and CS-B fibroblasts exposed to $4 \mathrm{~J} / \mathrm{m}^{2}$. These fluences of UVC cause more than $90 \%$ overall cell killing in the clonogenic assay $[87,113]$. On the other hand, exposure to these fluences triggered accelerated senescence, as evident from the sustained nuclear accumulation of p21 protein accompanied by the development of cells that exhibit flattened and enlarged morphology, cease to divide, retain viability and remain adherent for prolonged times (e.g., 7 days) after UVC exposure, and express high levels of the senescence marker senescence-associated- $\beta$-galactosidase [113]. Collectively, these results demonstrated that: (i) sustained nuclear accumulation of p21 associated with a proliferative block through the process of accelerated senescence is an integral component of the response of NER-proficient and -deficient human fibroblast cultures to relatively low fluences of UVC that are typically used in the clonogenic assay; and (ii) apoptosis does not appear to contribute significantly to the loss of clonogenic potential of non-transformed human fibroblasts exposed to such fluences of UVC.

In short, our findings underscore accelerated senescence as an important response triggered by physiologicallyrelevant fluences of UVC in human fibroblast cultures with differing NER capabilities. Further studies are warranted to elucidate the contribution of accelerated senescence in protecting against skin cancer and other deleterious effects of sunlight that are known to be associated with its UV component [114, 115].

What is the consequence of UV exposure in LFS cells that fail to implement p53-mediated responses? We reported that LFS fibroblasts and XP complementation group $\mathrm{E}$ fibroblasts exhibit a similar DNA repair deficiency after UV exposure, suggesting a relationship between the p53 and XPE proteins [87]. Subsequently, p53 was shown to regulate the $D D B-2$ gene, which is mutated in a subset of XPE patients [116, 117]. NER deficiency in XPE fibroblasts is associated with increased UV sensitivity in the clonogenic assay as compared to normal fibroblasts. This response is consistent with the notion that slow removal of bulky lesions in the former cells will provide a stronger and more persistent signal, compared with NER-proficient cells, for p53 activation, resulting in an elevated loss of clonogenic potential through p53-mediated apoptosis/accelerated senescence. Paradoxically, however, when compared to normal fibroblasts, LFS fibroblasts with XPE-like NER deficiency exhibit UV resistance in the clonogenic assay [87]. We proposed that, upon UV exposure, the signal (i.e., bulky DNA damage) for activating the p53-mediated events in LFS fibroblasts is as strong and as persistent as in XPE fibroblasts. LFS fibroblasts, however, respond poorly to the signal as a result of their compromised wild-type p53 function, resulting in the propagation of cells that retain clonogenic potential despite carrying high levels of genomic instability such as bulky DNA lesions.

\section{Ionizing Radiation-Triggered Apoptosis and Accelerated Senescence in ATM-Proficient and -Deficient Cells}

It is well documented that activation of the p53 pathway after exposure to ionizing radiation is triggered by DSBs and is primarily mediated by the ATM kinase (Fig. (1)). Accordingly, AT cells show a marked deficiency in activating p53 and p53-mediated responses such as DNA repair $[8,74]$ and cell cycle checkpoints $[8,69,118]$ after 
radiation exposure. In the same vein, AT cells would be expected to display a low propensity, compared to ATMproficient cells, to undergo p53-mediated apoptosis in response to radiation exposure. This expectation, together with the well-established radiation hyper-sensitivity response of AT cells when evaluated by the clonogenic assay, led to the notion that radiation exposure may result in persistent DNA lesions in AT cells due to defective ATM/p53mediated DNA repair, resulting in accumulation of "secondary" DNA lesions capable of triggering p53 accumulation at late times post-irradiation through an ATMindependent mechanism, followed by p53-mediated apoptosis [119]. In apparent support of this model, some reports observed AT cells to be more sensitive than normal cells to undergo apoptosis after exposure to ionizing radiation [120, 121]. These studies, however, involved SV40-transformed fibroblast cell lines in which the wildtype p53 function is severely compromised, if not absent. In studies reported by us, however, we were unable to demonstrate any significant apoptosis in non-transformed ATM-proficient and -deficient human fibroblast strains after exposure to a wide range of radiation doses that cause $\leq 99 \%$ loss of colony forming ability [122]. It is possible that the increased clonogenic radiosensitivity of AT cells might reflect an elevated, ATM-independent, nuclear accumulation of p21 at late time after radiation exposure, resulting in down-regulation of apoptosis coupled with growth arrest through accelerated senescence, leading to increased loss of clonogenic potential post-irradiation as compared to normal cells. We are currently testing this model.

\section{Endopolyploidy in Genome-Instability Syndrome Patients}

Although apoptosis has been the focus of most studies on cellular responses to genotoxic stress, it is becoming increasingly clear that accelerated senescence is also a major event triggered by relatively low doses of genotoxic agents in a variety of cell types, particularly in cells derived from patients with premature aging disorders which have a low threshold for undergoing senescence. It is also widely understood that bypass of apoptosis and accelerated senescence following genotoxic stress can lead to the development of cells with extensive genetic abnormalities, encompassing mononucleated and multinucleated endopolyploid giant cells [37-43]. As alluded to earlier, a subset of endopolyploid cells may undergo a complex series of neotic/mitotic cycles, resulting in the genesis of karyoplast cells that exhibit stem cell-like properties, which may in turn give rise to malignant and therapy-resistant descendents (Fig. (3)). In addition, like endopolyploid cells, human cells that have undergone senescence might also enter the neotic/mitotic cycles leading to the emergence of karyoplasts [39].

Whether this complex fate of endopolyploid and senescent cells leading to the genesis of karyoplast cells is an artifact of tissue culture or it also occurs in vivo is currently unknown. Assuming that these processes also take place in vivo, then it is reasonable to speculate that the highly cancerprone nature of some human genome instability disorders might be, at least in part, associated with the genesis of karyoplast cells and their progenies. This intriguing hypothesis remains to be tested.

\section{CONCLUDING REMARKS}

Defects in major players in the DNA surveillance networks are the underlying cause for numerous debilitating human genetic disorders that are characterized by genomic instability, premature aging, and cancer proneness. Cells derived from patients with such disorders exhibit aberrant responses to genotoxic agents as a result of deregulated p53 signaling in general, and p21-mediated accelerated senescence in particular. Recent studies with different murine and human cell lines have revealed that genotoxic stress can trigger the development of endopolyploid giant cells, a subset of which can serve as a "factory" for the genesis of karyoplasts exhibiting certain stem cell-like properties, which can in turn give rise to malignant descendents. Further research is warranted to test the intriguing possibility that marked cancer proneness of patients with some genome instability disorders might be associated with the emergence of karyoplasts and their progenies.

\section{ACKNOWLEDGEMENTS}

Work in the authors' laboratories was supported by the Canadian Institutes of Health Research, the Alberta Cancer Board Research Initiative Program, and the Canadian Breast Cancer Foundation - Prairies/NWT Chapter.

\section{ABBREVIATIONS}

\begin{tabular}{|c|c|c|}
\hline ASK-1 & $=$ & Apoptosis signal-regulating kinase 1 \\
\hline AT & $=$ & Ataxia telangiectasia \\
\hline ATLD & $=$ & AT-like disorder \\
\hline ATM & $=$ & AT mutated \\
\hline ATR & $=$ & ATM and Rad3-related \\
\hline $\mathrm{BAX}$ & $=$ & BCL-2-Associated X Protein \\
\hline BS & $=$ & Bloom Syndrome \\
\hline $\mathrm{CDK}$ & $=$ & Cyclin-dependent kinase \\
\hline CS & $=$ & Cockayne syndrome \\
\hline DSB & $=$ & DNA double strand break \\
\hline FA & $=$ & Fanconi anemia \\
\hline GGR & $=$ & Global genome repair \\
\hline LFS & $=$ & Li-Fraumeni syndrome \\
\hline MAPK & $=$ & Mitogen-activated protein kinase \\
\hline NBS & $=$ & Nijmegen breakage syndrome \\
\hline NER & $=$ & Nucleotide excision repair \\
\hline PCNA & $=$ & Proliferating cell nuclear antigen \\
\hline $\mathrm{pRB}$ & $=$ & Retinoblastoma protein \\
\hline PUMA & $=$ & p53 upregulated modulator of apoptosis \\
\hline RTS & $=$ & Rothmund-Thompson syndrome \\
\hline TCR & $=$ & Transcription-coupled repair \\
\hline
\end{tabular}




$\begin{array}{ll}\text { TTD } & =\text { Tricothiodystrophy } \\ \mathrm{UV} & =\text { Ultraviolet light } \\ \mathrm{WS} & =\text { Werner syndrome } \\ \mathrm{XP} & =\text { Xeroderma pigmentosum }\end{array}$

\section{REFERENCES}

[1] Cho Y, Gorina S, Jeffrey PD, Pavletich NP. Crystal structure of a p53 tumor suppressor-DNA complex: understanding tumorigenic mutations. Science 1994; 265: 346-55.

[2] Michael D, Oren M. The p53-Mdm2 module and the ubiquitin system. Semin Cancer Biol 2003; 13: 49-58.

[3] Ljungman M. Dial 9-1-1 for p53: Mechanisms of p53 activation by cellular stress. Neoplasia 2000; 2: 208-25.

[4] Meek DW. The p53 response to DNA damage. DNA Repair 2004; 3: 1049-56.

[5] Melchior F, Hengst L. SUMO-1 and p53. Cell Cycle 2002; 1: 2459.

[6] Latonen L, Laiho M. Cellular UV damage responses - Functions of tumor suppressor p53. Biochim Biophys Acta 2005; 755: 71-89.

[7] Lacroix M, Toillon RA, Leclercq G. p53 and breast cancer, an update. Endocr Relat Cancer 2006; 13: 293-325.

[8] Rotman G, Shiloh,Y. ATM: a mediator of multiple responses to genotoxic stress. Oncogene 1999; 18: 6135-44.

[9] Giaccia AJ, Kastan MB. The complexity of p53 modulation: emerging patterns from divergent signals. Genes Dev 1998; 12: 2973-83.

[10] Mirzayans R, Murray D. Cellular senescence: Implications for cancer therapy. In: Garvey RB Ed. New Research on Cell Aging. Hauppauge NY, Nova Science Publishers, Inc., 2007; pp. 1-64.

[11] Lane, DP. p53 from pathway to therapy. Carcinogenesis 2004; 25 : 1077-81.

[12] Roninson IB, Broude EV, Chang BD. If not apoptosis, then what? Treatment-induced senescence and mitotic catastrophe in tumor cells. Drug Resist Updates 2001; 4: 303-13.

[13] Mirzayans R, Scott A, Cameron M, Murray D. Induction of accelerated senescence following exposure to ionizing radiation in human solid tumor-derived cell lines expressing wild-type TP53. Radiat Res 2005; 163: 53-62.

[14] Akhtar RS, Geng Y, Klocke BJ, et al. BH3-Only proapoptotic Bcl2 family members Noxa and Puma mediate neural precursor cell death. J Neurosci 2006; 26: 7257-64.

[15] Fuster JJ, Sanz-González SM, Moll UM, Andres V. Classic and novel roles of p53: prospects for anticancer therapy. Trends Mol Med 2007; 13: 192-9.

[16] Murray D, Mirzayans R. Role of p53 in the repair of ionizing radiation-induced DNA damage. In: Landseer BR Ed. New Research on DNA Repair. Hauppauge, NY, Nova Science Publishers, Inc., 2007; pp. 325-73.

[17] Jongmans W, Vuillaume M, Kleijer WJ, Lakin ND, Hall J. The p53-mediated DNA damage response to ionizing radiation in fibroblasts from ataxia-without-telangiectasia patients. Int J Radiat Biol 1998; 74: 287-95.

[18] Sturzbecher HW, Donzelmann B, Henning W, Knippschild U, Buchhop S. p53 is linked directly to homologous recombination processes via RAD51/RecA protein interaction. EMBO J 1996; 15: 1992-2002.

[19] Al Rashid ST, Dellaire G, Cuddihy A, et al. Evidence for the direct binding of phosphorylated p53 to sites of DNA breaks in vivo. Cancer Res 2005; 65: 10810-21.

[20] Ford JM. Regulation of DNA damage recognition and nucleotide excision repair: another role for p53. Mutat Res 2005; 577: 195202.

[21] Asada M, Yamada T, Ichijo H, et al. Apoptosis inhibitory activity of cytoplasmic $\mathrm{p} 21^{\mathrm{Cip} / \mathrm{WAF} 1}$ in monocytic differentiation. EMBO J 1999; 18: 1223-34.

[22] Ruaro EM, Collavin L, Sal GD, et al. A proline-rich motif in p53 is required for transactivation-independent growth arrest as induced by Gas1. Proc Natl Acad Sci USA 1997; 94: 4675-80.

[23] Komarova EA, Diatchenko L, Rokhlin OW, et al. Stress-induced secretion of growth inhibitors: a novel tumor suppressor function of p53. Oncogene 1998; 17: 1089-96.

[24] Rousseau D, Cannella D, Boulaire J, Fitzgerald P, Fotedar A, Fotedar R. Growth inhibition by CDK-cyclin and PCNA binding domains of $\mathrm{p} 21$ occurs by distinct mechanisms and is regulated by ubiquitin-proteasome pathway. Oncogene 1999; 18: 4313-25.

Roninson IB. Tumor cell senescence in cancer treatment. Cancer Res 2003; 63: 2705-15.

Chuang L, Ian HI, Koh TW, Ng HH, Xu G, Li BF. Human DNA(cytosine-5) methyltransferase-PCNA complex as a target for p21 ${ }^{\mathrm{WAF} 1}$. Science 1997; 277: 1996-2000.

[27] Zhou BP, Hung MC. Novel targets of Akt, p21 ${ }^{\mathrm{Cip} 1 / \mathrm{WAF} 1}$, and MDM2. Semin Oncol 2002; 29 (Suppl.11): 62-70.

[28] Suzuki A, Tsutomi Y, Yamamoto N, Shibutani T, Akahane K. Mitochondrial regulation of cell death: mitochondria are essential for procaspase 3-p21 complex formation to resist Fas-mediated cell death. Mol Cell Biol 1999; 19: 3842-7.

[29] Broude EV, Swift ME, Vivo C, et al. p21 $1^{\text {Waf } 1 / \text { Cip } 1 / \text { dil }}$ mediates retinoblastoma protein degradation. Oncogene 2007; 26: 6954-58

[30] Erenpreisa J, Cragg MS. Mitotic death: a mechanism of survival? A review. Cancer Cell Int 2001; 1: 1-7.

[31] Erenpreisa JA, Cragg MS, Fringes B, Sharakhov I, Illidge TM Release of mitotic descendants by giant cells from irradiated Burkitt's lymphoma cell lines. Cell Biol Int 2000; 24: 635-48.

[32] Illidge TM, Cragg MS, Fringes B, Olive P, Erenpresia JA. Polyploid giant cells provide a survival mechanism of p53 mutant cells after DNA damage. Cell Biol Int 2000; 24: 621-33.

[33] Ivanov A, Cragg MS, Erenpreisa J, Emzinsh D, Lukman H, Illidge TM. Endopolyploid cells produced after severe genotoxic damage have the potential to repair DNA double strand breaks. J Cell Science 2003; 116: 4095-106

[34] Erenpreisa J, Ivanov A, Wheatley SP, et al. Endopolyploidy in irradiated p53-deficient tumour cell lines: Persistence of cell division activity in giant cells expressing Aurora-B kinase. Cell Biol Int 2008: 1-13.

[35] Sundaram M, Guernsey DL, Rajaraman MM, Rajaraman R. Neosis: A novel type of cell division in cancer. Cancer Biol Ther 2004; 3: 207-18.

[36] Rajaraman R, Rajaraman MM, Rajaraman SR, Guernsey RL. Neosis - a paradigm of self-renewal in cancer. Cell Biol Int 2005; 29: 1084-97.

[37] Parris GE. Clinically significant cancer evolves from transient mutated and/or aneuploid neoplasia by cell fusion to form unstable syncytia that give rise to ecologically viable parasite species. Med Hypotheses 2005; 65: 846-50.

[38] Rajaraman R, Guernsey DL, Rajaraman MM, Rajaraman SR. Stem cells, senescence, neosis and self-renewal in cancer. Cell Biol Int 2006; 29: 1084-97.

[39] Walen KH. Spontaneous cell transformation: karyoplasts derived from multinucleated cells produce new cell growth in senescent human epithelial cell cultures. In Vitro Cell Dev Biol Anim 2004; 40: $150-8$.

[40] Walen KH. Budded karyoplasts from multinucleated fibroblast cells contain centrosomes and change their morphology to mitotic cells. Cell Biol Int 2005; 29: 1057-65.

[41] Martin F, Solary E. Tumor cell resistance to DNA-damaging agents: from apoptosis to neosis. Curr Med Chem Anticancer Agents 2004; 4: 461-3.

[42] Navolanic PM, Akula SM, McCubrey JA. Neosis and its potential role in cancer development and chemoresistance. Cancer Biol Ther 2004; 3: 219-320.

[43] Erenpreisa J, Wheatley D. Editorial: Endopolyploidy in development and cancer; "survival of the fattest?" Cell Biol Inter 2005; 29: 981-2.

[44] Paterson MC, Gentner NE, Middlestadt MV, Weinfeld M. Cancer predisposition, carcinogen hypersensitivity, and aberrant DNA metabolism. J Cell Physiol Suppl 1984; 3: 45-62.

[45] Cleaver JE. Cancer in xeroderma pigmentosum and related disorders of DNA repair. Nat Rev Cancer 2005; 5: 564-73.

[46] Vava-Grosjean L, Sarasin A. The role of UV induced lesions in skin carcinogenesis: an overview of oncogene and tumor suppressor gene modifications in xeroderma pigmentosum skin tumors. Mutat Res 2005; 571: 43-56.

[47] McCormick JJ, Kateley-Kohler S, Watanabe M, Maher VM Abnormal sensitivity of human fibroblasts from xeroderma pigmentosum variants to transformation to anchorage independence by ultraviolet radiation. Cancer Res 1986; 46: 489-92.

[48] Lambert WC, Lambert MW. DNA repair deficiency and cancer in xeroderma pigmentosum. Cancer Rev 1987; 7: 56-81. 
[49] Hanawalt PC. Subpathways of nucleotide excision repair and their regulation. Oncogene 2002; 21: 8949-56.

[50] Broughton BC, Cordonnier A, Kleijer WJ, et al. Molecular analysis of mutations in DNA polymerase eta in xeroderma pigmentosumvariant patients. Proc Natl Acad Sci USA 2002; 99: 815-20.

[51] Licht CL, Stevnsner T, Bohr VA. Cockayne syndrome group B cellular and biochemical functions. Am J Hum Genet 2003; 73: 1217-39.

[52] Nance MA, Berry SA. Cockayne syndrome: review of 140 cases. Am J Med Genet 1992; 42: 68-84.

[53] Friedberg, EC. Cockayne syndrome - a primary defect in DNA repair, transcription, both or neither? Bioessays, 1996; 18, 731-8.

[54] Henning KA, Li L, Iyer N, et al. The Cockayne syndrome group A gene encodes a WD repeat protein that interacts with CSB protein and a subunit of RNA polymerase II TFIIH. Cell 1995; 82: 555-64.

[55] Citterio E, Van DVB, Schnitzler G, et al. ATP-dependent chromatin remodeling by the Cockayne syndrome B DNA repairtranscription-coupling factor. Mol Cell Biol 2000; 20: 7643-7653.

[56] Balajee AS, May A, Dianov GL, Friedberg EC, Bohr VA. Reduced RNA polymerase II transcription in intact and permeabilized Cockayne syndrome group B cells. Proc Natl Acad Sci USA 1887; 94: 4306-11.

[57] Selby CP, Sancar A. Cockayne syndrome group B protein enhances elongation by RNA polymerase II. Proc Natl Acad Sci USA 1997; 94: 11205-9.

[58] Dianov G, Bischoff C, Sunesen M, Bohr VA. Repair of 8oxoguanine in DNA is deficient in Cockayne syndrome group B cells. Nucleic Acids Res 1999, 27: 1365-8.

[59] Leadon SA, Cooper PK. Preferential repair of ionizing radiationinduced damage in the transcribed strand of an active human gene is defective in Cockayne syndrome. Proc Natl Acad Sci USA 1993; 90: 10499-503.

[60] Cooper PK, Nouspikel T, Clarkson SG, Leadon SA. Defective transcription-coupled repair of oxidative base damage in Cockayne syndrome patients from XP group G. Science 1997; 275: 990-3.

[61] Le Page F, Kwoh EE, Avrutskaya A, et al. Transcription-coupled repair of 8-oxoguanine: requirement for XPG, TFIIH, and CSB and implications for Cockayne syndrome. Cell 2000; 101: 159-71.

[62] Itin PH, Pittelkow MR. Trichothiodystrophy: Review of sulfurdeficient brittle hair syndromes and association with the ectodermal dysplasias. J Am Acad Dermatol 1990; 20: 705-17.

[63] Stefanini M, Vermeulen W, Weeda G, et al. A new nucleotide-excision-repair gene associated with the disorder trichothiodystrophy. Am J Hum Genet, 1993; 53: 817-21.

[64] Weeda G, Eveno E, Donker I, et al. Amutation in the XPB:ERCC3 DNA repair transcription gene, associated with trichothiodystrophy. Am J Hum Genet 1997; 60: 320-9.

[65] Gatti RA, Boder E, Vinters HV, Sparkes RS, Norman A, Lange K. Ataxia-telangiectasia: an interdisciplinary approach to pathogenesis. Medicine 1991; 70: 99-117.

[66] Brown KD, Barlow C, Wynshaw-Boris A. Multiple ATMdependent pathways: an explanation for pleiotropy. Am J Hum Genet 1999; 64: 46-50.

[67] Paterson MC, Smith PJ. Ataxia telangiectasia: An inherited human disorder involving hypersensitivity to ionizing radiation and related DNA-damaging chemicals. Annu Rev Genet 1979; 13: 291-318.

[68] Khanna KK. Cancer risk and the ATM gene: a continuing debate. J Natl Cancer Inst 2000; 92: 795-802.

[69] Lavin MF, Khanna KK. ATM: The protein encoded by the gene mutated in the radiosensitive syndrome ataxia-telangiectasia. Int $\mathbf{J}$ Radiat Biol 1999; 75: 1201-14.

[70] Matsuoka S, Ballif BA, Smogorzewska A, et al. ATM and ATR substrate analysis reveals extensive protein networks responsive to DNA damage. Science 2007; 316: 1160-6.

[71] Paull TT, Rogakou EP, Yamazaki V, Kirchgessner CU, Gellert M, Bonner WM. A critical role for histone H2AX in recruitment of repair factors to nuclear foci after DNA damage. Curr Biol 2000; 10: 886-95.

[72] Celeste A, Petersen S, Romanienko PJ, et al. Genomic instability in mice lacking histone H2AX. Science 2002; 296: 922-7.

[73] Kühne M, Riballo E, Rief N, Rothkamm K, Jeggo PA, Löbrich M. A double-strand break repair defect in ATM-deficient cells contributes to radiosensitivity. Cancer Res 2004; 64: 500-8.

[74] Mirzayans R, Severin D, Murray D. Relationship between DNA double strand break rejoining and cell survival following exposure to ionizing radiation in human fibroblast strains with differing
ATM/p53 function: implications for the evaluation of clinical radiosensitivity. Int J Radiat Oncol Biol Phys 2006; 66:1498-505.

[75] Mirzayans R, Paterson MC. Correction of radioresistant DNA synthesis in ataxia telangiectasia fibroblasts by prostaglandin $\mathrm{E}_{2}$ treatment. Environ Mol Mutagen 2001, 38: 191-9.

[76] Tauchi H, Matsuura S, Kobayashi J, Sakamoto S, Komatsu K. Nijmegen breakage syndrome gene, NBS1, and molecular links to factors for genome stability. Oncogene 2002; 21: 8967-80.

[77] Yamazaki V, Wegner RD, Kirchgessner CU. Characterization of cell cycle checkpoint responses after ionizing radiation in Nijmegen breakage syndrome cells. Cancer Res 1998; 58: 2316-22.

[78] Kobayashi J, Tauchi H, Sakamoto S, et al. NBS1 localizes to gamma-H2AX foci through interaction with the FHA/BRCT domain. Curr Biol 2002; 12: 1846-51.

[79] Stewart GS, Maser RS, Stankovic T, et al. The DNA double-strand break repair gene hMRE11 is mutated in individuals with an ataxiatelangiectasia-like disorder. Cell 1999; 99: 577-87.

[80] Li FP, Fraumeni JF Jr, Mulvihill JJ, et al. A cancer family syndrome in twenty-four kindreds. Cancer Res 1988; 48: 5358-62.

[81] Malkin D, Li FP, Strong LC, et al. Germ line p53 mutations in a familial syndrome of breast cancer, sarcomas, and other neoplasms. Science 1990; 250: 1233-8.

[82] Brown LT, Sexsmith E, Malkin D. Identification of a novel PTEN intronic deletion in Li-Fraumeni syndrome and its effect on RNA processing. Cancer Genet Cytogenet 2000; 123: 65-8

[83] Bell DW, Varley JM, Szydlo TE, et al. Heterozygous germ line hCHK2 mutations in Li-Fraumeni syndrome. Science 1999; 286: 2433-4.

[84] Wang XW, Yeh H, Schaeffer L, et al. P53 modulation of TFIIHassociated nucleotide excision repair activity. Nature Genet 1995; 10: 188-95

[85] Ford JM, Hanawalt PC. Li-Fraumeni syndrome fibroblasts homozygous for p53 mutations are deficient in global DNA repair but exhibit normal transcription-coupled repair and enhanced UV resistance. Proc Natl Acad Sci USA 1995; 92: 8876-80.

[86] Mirzayans R, Enns L, Dietrich K, Barley RD, Paterson MC. Faulty DNA polymerase $\delta / \varepsilon$-mediated excision repair in response to $\gamma$ radiation or ultraviolet light in p53-deficient fibroblast strains from affected members of a cancer-prone family with Li-Fraumeni syndrome. Carcinogenesis 1996; 17: 691-8.

[87] Barley RDC, Enns L, Paterson MC, Mirzayans R. Aberrant p21 $1^{W A F 1}$-dependent growth arrest as the possible mechanism of abnormal resistance to ultraviolet light cytotoxicity in Li-Fraumeni syndrome fibroblast strains heterozygous for TP53 mutations. Oncogene 1998; 17: 533-43.

[88] Martin GM, Sprague CA, Epstein CJ. Replicative life-span of cultivated human cells. Effects of donor's age, tissue, and genotype. Lab Invest 1970; 23: 86-92.

[89] Nakayama H. RecQ family helicases: roles as tumor suppressor proteins. Oncogene 2002; 21: 9008-21.

[90] Gray MD, Shen JC, Kamath-Loeb AS, et al. The Werner syndrome protein is a DNA helicase. Nat Genet 1997; 17: 100-3.

[91] Huang S, Li B, Gray MD, Oshima J, Mian IS, Campisi J. The premature ageing syndrome protein, WRN, is a $3^{\prime} \rightarrow 5^{\prime}$ exonuclease. Nat Genet 1998; 20: 114-6.

[92] Kamath-Loeb AS, Shen JC, Loeb LA, Fry M. Werner syndrome protein. II. Characterization of the integral $3^{\prime} \rightarrow 5^{\prime}$ DNA exonuclease. J Biol Chem 1998; 273: 34145-50.

[93] Shen JC, Gray MD, Oshima J, Kamath-Loeb AS, Fry M, Loeb LA. Werner syndrome protein. I. DNA helicase and DNA exonuclease reside on the same polypeptide. J Biol Chem 1998; 273: 34139-44.

[94] Blander G, Kipnis J, Leal JF, Yu CE, Schellenberg GD, Oren M. Physical and functional interaction between p53 and the Werner's syndrome protein. J Biol Chem 1999; 274: 29463-69.

[95] Blander G, Zalle N, Leal JF, Bar-Or RL, Yu CE, Oren M. The Werner syndrome protein contributes to induction of p53 by DNA damage. FASEB J 2000; 14: 2138-40.

[96] Pichierri P, Rosselli F, Franchitto A. Werner's syndrome protein is phosphorylated in an ATR/ATM-dependent manner following replication arrest and DNA damage induced during the $S$ phase of the cell cycle. Oncogene 2003; 22: 1491-1500.

[97] Kaneko H, Kondo N. Clinical features of Bloom syndrome and function of the causative gene, BLM helicase. Exprt Rev Mol Diagn 2004; 3: 393-401.

[98] German J. Bloom's syndrome. XX. The first 100 cancers. Cancer Genet Cytogenet 1997; 93: 100-6. 
[99] German J. Bloom syndrome: a Mendelian prototype of somatic mutational disease. Medicine 1993; 72: 393-406.

[100] Ellis NA, Groden J, Ye TZ, et al. The Bloom's syndrome gene product is homologous to RecQ helicases. Cell 1995; 83: 655-66.

[101] Ababou M, Dutertre S, Lécluse Y, Onclercq R, Chatton B, AmorGuéret M. ATM-dependent phosphorylation and accumulation of endogenous BLM protein in response to ionizing radiation. Oncogene 2000; 19: 5955-63.

[102] Vennos EM, James WD. Rothmund-Thomson syndrome. Dermatol Clin 1995; 13: 143-50.

[103] Kitao S, Shimamoto A, Goto M, et al. Mutations in RECQL4 cause a sub-set of cases of Rothmund-Thomson syndrome. Nature Genet 1999; 22: 82-4.

[104] D'Andrea AD, Grompe M. The Fanconi anaemia/BRCA pathway. Nat Rev Cancer 2003; 3: 23-34.

[105] Tischkowitz MD, Hodgson SV. Fanconi anaemia. J Med Genet 2003; 40: 1-10.

[106] Niedernhofer LJ, Lalai AS, Hoeijmakers JH. Fanconi anemia (cross) linked to DNA repair. Cell 2005; 123: 1191-8.

[107] Gurtan AM, D'Andrea AD. Dedicated to the core: Understanding the Fanconi anemia complex. DNA Repair 2006; 5: 1119-25.

[108] Garcia-Higuera I, Taniguchi T, Ganesan S, et al. Interaction of the Fanconi anemia proteins and BRCA1 in a common pathway. Mol Cell 2001; 7: 249-62.

[109] Wang X, Andreassen PR, D'Andrea AD. Functional interaction of monoubiquitinated FANCD2 and BRCA2/FANCD1 in chromatin. Mol Cell Biol 2004, 24: 5850-62.

[110] Nakanishi K, Taniguchi T, Ranganathan V, et al. Interaction of FANCD2 and NBS1 in the DNA damage response. Nat Cel Biol 2002; 4: 913-20.

[111] Mirzayans R, Bashir S, Murray D, Paterson MC. Inverse correlation between p53 protein levels and DNA repair efficiency in human fibroblast strains treated with 4-nitroquinoline 1-oxide: evidence that lesions other than DNA strand breaks trigger the p53 response. Carcinogenesis 1999; 20: 941-6.

[112] Enns L, Murray D, Mirzayans R. Lack of correlation between DNA strand breakage and p53 protein levels in human fibroblast strains exposed to ultraviolet lights. Photochem Photobiol 2000; 72: 562-8.
[113] Mirzayans R, Scott A, Andrais B, Pollock S, Murray D. Ultraviolet light exposure triggers nuclear accumulation of $p 21^{\text {WAFI }}$ and accelerated senescence in human normal and nucleotide excision repair-deficient fibroblast strains. J Cell Physiol 2008; 215: 55-67.

[114] de Gruijl FR. Photocarcinogenesis: UVA vs. UVB radiation. Skin Pharmacol Appl Skin Physiol 2002; 15: 316-20.

[115] Bowden GT. Prevention of non-melanoma skin cancer by targeting ultraviolet-B-light signalling. Nat Rev Cancer 2004; 4: 23-35.

[116] Hwang BJ, Ford JM, Hanawalt PC, Chu G. Expression of the p48 xeroderma pigmentosum gene is p53-dependent and is involved in global genomic repair. Proc Natl Acad Sci USA 1999; 96: 424-8.

[117] Wakasugi M, Kawashima A, Morioka H, et al. DDB accumulates at DNA damage sites immediately after UV irradiation and directly stimulates nucleotide excision repair. J Biol Chem 2002; 277 : $1637-40$

[118] Mirzayans R, Famulski K, Enns L, Fraser M, Paterson MC Characterization of the signal transduction pathway mediating $\gamma$ ray-induced inhibition of DNA synthesis in human cells: indirect evidence for involvement of calmodulin but not protein kinase $\mathrm{C}$ nor p53. Oncogene 1995; 11: 1597-605.

[119] Enoch T, Norbury C. Cellular responses to DNA damage: Cellcycle checkpoints, apoptosis and the roles of p53 and ATM. Trends Biochem Sci 1995; 20: 426-30.

[120] Meyn MS, Strasfeld L, Allen C. Testing the role of p53 in the expression of genetic instability and apoptosis in ataxiatelangiectasia. Int J Radiat Biol 1994; 66 (6 Suppl): S141-149.

[121] Zhang Y, Dimtchev A, Dritschilo A, Jung M. Ionizing radiationinduced apoptosis in ataxia-telangiectasia fibroblasts. Roles of caspase-9 and cellular inhibitor of apoptosis protein-1. J Biol Chem 2001; 276: 28842-8.

[122] Enns L, Barley RD, Paterson MC, Mirzayans R. Radiosensitivity in ataxia telangiectasia fibroblasts is not associated with deregulated apoptosis. Radiat Res 1998; 150: 11-6.

[123] Baylin SB. Tying it all together: epigenetics, genetics, cell cycle, and cancer. Science. 1997; 277: 1948-9.

This is an open access article licensed under the terms of the Creative Commons Attribution Non-Commercial License (http://creativecommons.org/licenses/by$\mathrm{nc} / 3.0 /)$, which permits unrestricted, non-commercial use, distribution and reproduction in any medium, provided the work is properly cited. 